\title{
VARIANT RADIAL ARTERY: A CASE REPORT
}

\author{
K. Manivannan ${ }^{1}$, N. Shakuntala Rao², Gangadhara3 ${ }^{3}$ H. R. Krishna Rao ${ }^{4}$
}

\section{HOW TO CITE THIS ARTICLE:}

K. Manivannan, N. Shakuntala Rao, Gangadhara, H. R. Krishna Rao. "Variant Radial Artery: A Case Report". Journal of Evolution of Medical and Dental Sciences 2014; Vol. 3, Issue 25, June 23; Page: 7067-7072, DOI: $10.14260 /$ jemds $/ 2014 / 2860$

ABSTRACT: During routine dissection of cadavers in the anatomy department for teaching and demonstration to medical students, the upper limb of one of the cadavers showed an arterial anomaly. An artery arose from the brachial artery at the level of upper part of the right arm. This artery then passed downwards and laterally and at the level of the elbow joined the radial artery which was given off normally at the termination of brachial artery. The radial artery passed behind the tendon of biceps brachii to join the artery which came from the brachial artery from above a little inferior to the level of elbow joint. Arterial variations in the upper limb were first described in the eighteenth century. Many studies have attempted to describe the arterial variations that occur in the upper limb on the basis of embryological hypotheses. In this case report an attempt has been made to correlate the findings and give a terminology to the variation that has been observed. The previously reported incidence of such a variation in the arterial pattern has been less than $0.7 \%$.The clinical importance of arterial variations cannot be underestimated or overlooked as they can result in problems during surgical procedures.

KEYWORDS: superficial brachial artery, accessory radial artery, brachioradial artery.

INTRODUCTION: The arteries of the upper limb develop from principal arteries. They form anastomoses and networks to supply their respective regions. The subclavian artery is the axis artery of the upper limb and develops from the lateral branch of the 7 th intersegmental artery. It persists as the subclavian artery. It then passes into the forearm and terminates as a deep plexus in the developing hand. The original axial artery persists as the anterior interosseous artery in the forearm and the deep palmar arch in the hand. Between the developing radius and ulna a branch arises from the axis artery and passes dorsally as the posterior interosseous artery.

Another branch accompanies the median nerve to the hand and ends in a superficial capillary plexus. This is the median artery in the forearm. The arteries of forearm appear later as the radial and ulnar arteries. At first the radial artery arises proximal to ulnar artery and supplies biceps by crossing in front of the median nerve. After it establishes a new connection with the main trunk at or near the level of origin of ulnar artery the upper portion of the radial artery disappears. The ulnar artery on reaching the hand connects with the superficial palmar plexus which forms the superficial palmar arch. The median artery loses its connections with the superficial capillary plexus and is reduced to a small vessel. The radial artery joins the deep palmar arch by passing to the dorsal surface of the hand. It gives off dorsal digital branches, traverses the first intermetacarpal space. ${ }^{1}$

Arterial variations in the upper limb were first described in the eighteenth century by Von Haller (1813). Many studies on the variations focused on embryological basis and many hypotheses were put forward. One such theory was that of Singer ${ }^{2}$ which has been widely accepted. Singer has stated that adult pattern develops from a main axial trunk from the axilla to fingers. This is represented by brachial and interosseous artery. Then new arteries arise by angiogenesis forming the 
median artery, ulnar artery and the superficial brachial artery. Finally the brachial and superficial brachial anastomose at elbow level forming the initial part of radial artery. Later the part above the anastomosis regresses and the adult radial artery forms. Thus Singer has described five stages in which in a successive manner an axial artery, a median artery, an ulnar artery, a radial artery develop in the first four stages and then finally a stage where portions of the arteries regress or disappear and the adult pattern is established. Therefore when any anomalous artery is observed it implicates a disturbance or delay in the stages of normal pattern formation.

OBSERVATION: An artery arose from the brachial artery at the level of upper part of the right arm. This artery then passed downwards and laterally and at the level of the elbow joined the radial artery (fig. 2) which was given off normally at the termination of brachial artery. The radial artery passed behind the tendon of biceps brachii (fig. 1) to join the artery which came from the brachial artery from above a little inferior to the level of elbow joint.

DISCUSSION: M. Rodriguez et $\mathrm{al}^{3}$ has observed the formation of arterial system in the upper limb in 112 human embryos between stages of 12 and 23. They have described a dual process of formation. The initial capillary plexus that supplies the upper limb from the dorsal aorta undergoes an enlargement and differentiation of selected parts in a proximal to distal sequence. An initial capillary plexus originates from the dorsal aorta. It enters the limb bud during stage 12 when limb bud begins its outgrowth. This plexus develops at the same rate as the limb. Enlargement and differentiation of the capillary plexus begins at stage 13 . The subclavian and axillary arteries have differentiated by stage 15 . By stage 17 the brachial artery as far as the elbow has formed. The forearm arteries form at stage 18 except the distal part of radial artery. The whole arterial pattern is finally formed by stage 21.

Rodriguez et al $2001^{3}$ concluded that an endothelial tube after getting its muscular coat loses its remodeling ability. Therefore due to persistence, enlargement and differentiation of certain capillary vessels from the initial plexus arterial variations would arise. They would have otherwise normally remained as capillaries or regressed. When the definitive wall morphology has not been established it would make it possible to form variations. This theory does not agree with the sprouting theory of variations which describes the artery as a new artery that sprouts from an aberrant site. In the present case applying the development criteria of Rodriguez et al ${ }^{3}$ the artery is assumed to have developed during stage 18 to 21 in the embryo.

This differentiation takes place along with development of the skeletal system. They have reported an incidence of $0.6 \%$ of accessory brachial, $7.7 \%$ of superficial brachial and $14 \%$ of brachioradial. They have suggested that the variations arise when parts of the initial network of arteries that would normally disappear enlarge, differentiate and persist.

Shiny et $\mathrm{al}^{4}$ in their study reported a superficial brachioradial artery that took origin from axillary artery. In our study the artery did not take origin from the axillary artery. The origin of variant arteries was important for naming the artery. An attempt was made by Rodriguez et al to describe terminology of the variant arteries based on previous criteria. One such attempt that names the arteries was based on topographical criteria. An artery that arises from the arm after the brachial artery was named superficial brachial artery. The name does not refer to an artery that crosses the forearm. Since it originated in the arm it was considered to represent the brachial artery only. It was 
supposed to pass in front of the median nerve and branch into forearm arteries at the elbow. The incidence of this kind of variation was reported to be $4.8 \%{ }^{5}$

In the present case the origin was in the arm and from the brachial artery and it was also in the superficial fascia. (fig. 2) Therefore the term superficial brachial artery can be given. The course of the artery in the arm was lateral to the median nerve. The brachial artery proper passed lateral to the median nerve through its course in the arm.

Of arteries that arise in the arm the name accessory brachial artery can be given if the artery originates from the brachial or axillary artery and rejoins the brachial artery in the distal third of the arm before it divides into the usual forearm arteries. In this case the artery took origin from brachial artery but did not rejoin the main artery. It joined the radial artery below the level of the elbow. The common observation noted with the variation of the artery from the arm was the course from the upper third of the brachial artery, superficial to median nerve and behind bicipital aponeurosis at the elbow. In this case the main radial artery passed behind the tendon of biceps. (fig. 1)

A persistent superficial brachial artery has been considered as a high origin of radial artery in a study by Vandana Mehta et al. $^{6}$ In this case the variant artery and the original radial artery are continuous at the elbow. This can be considered as a high origin of radial artery. Radial artery usually begins in the cubital fossa about $1 \mathrm{~cm}$ below the bend of the elbow at the level of the neck of the radius just medial to the tendon of biceps brachii muscle, and terminates in the hand by forming the deep palmar arch after anastomosing with the deep branch of the ulnar artery ${ }^{1}$

Persisting embryological vessels may have a haemodynamic basis. The superficial system of vessels may persist due to haemodynamic persistence over deep vesels. ${ }^{7,8}$ Other factors like genetic influences fetal position in utero, first limb movement, unusual musculature are deemed to be prevalent causes of such variation.

In a standard textbook ${ }^{9}$ the term" Vasa Aberrentia" has been used to describe a long vessel that connects the brachial artery with the axillary artery or Radial artery.

D'Costa $S$ et al 10 have reported a superficial arterial pattern in an adult male resembling a superficial brachio-ulno-radial artery (SBUR). They observed that the median nerve crossed the superficial brachial artery (SBA) from the posterior to the medial side and again posterior at the cubital fossa. The superficial brachial artery divided into superficial radial and superficial ulnar arteries. The superficial radial artery passed deep to the extensor tendons of the thumb. They observed that the superficial radial artery gave origin to the radial recurrent artery and the common interosseous trunk.

Fuss FK et al ${ }^{11}$ studied the arterial pattern in 100 right and 100 left upper limbs. In their sample normal brachial artery was found in $83 \%$. They found a superficial brachial artery in $17 \%$. They described in their sample three main types of the superficial brachial artery. The types were described as A.brachialis superficialis superior in 6\%, A. brachialis superficialis media in $1.5 \%$ and A. brachialis superficialis inferior in 9.5\%.

A study by Sajja LR et al ${ }^{12}$ reviewed the role of radial artery for coronary bypass grafting. The knowledge of variations in this artery is therefore important for such procedures.

CONCLUSION: In this case the radial artery gave branches to the muscles near its termination. It can be considered accessory radial artery though it had its origin in the arm considering the importance of the arterial supply to the muscles. 
In the present case the artery passed behind the tendon of biceps and this is considered important in case of surgeries of the upper limb. We have to decipher whether the relationship of the artery to the tendon of biceps could affect the circulation. Therefore it might have resulted in the persistence of the superficial vessel to compensate for the probable deficiency in circulation. Diagnostic procedures could be difficult and fatal if the variant arteries are present. They could pose a problem in reconstructive surgeries. The present case report highlights the importance of variations in arterial pattern of upper limb.

\section{REFERENCES:}

1. Susan Standring \& Patricia Collins. The Anatomical Basis of Clinical practice, Gray's Anatomy $40^{\text {th }}$ edition. The development of upper limb 905

2. Singer E. Embryological pattern persisting in the arteries of the arm. Anat Rec. 1933; 55: 403-9

3. Rodriguez-Niedenführ M, Burton GJ, Deu J, Sañudo. Development of the arterial pattern in the upper limb of staged human embryos: Normal development and anatomic variations. J Anat Br. 2001; 199: 407-17.

4. Shiny Vinila B. H., Sangeeta M, Sanikop M. B. and Venkateshu K. V. Superficial brachioradial artery with its embryological basis - a case report. International Journal of Basic and Applied Medical Sciences 2013: Vol. 3(1) 10-13

5. Rodríguez-Niedenführ M, Vázquez T, Nearn L, Ferreira B, Parkin I, Sañudo Variations of the arterial pattern in the upper limb revisited: A morphological and statistical study, with a review of the literature. J Anat Am. 2001; 199: 547-66.

6. Vandana Mehta, Jyoti Arora, R K Suri, Gayatri Rath. Unilateral Anomalous Arterial Pattern of Human Upper Limb. Sultan Qaboos Univ Med J. 2008 July; 8(2): 227-230.

7. Rodriguez-Baeza A, Nebot J, Ferreira B, Reina F, Perez J, Sann Udo, et al. An anatomical study and ontogenic explanation of 23 cases with variations in the main pattern of the human brachio-antebrachial arteries. J Anat. 1995; 187: 473-9.

8. Rodríguez-Niedenführ M, Vázquez T, Parkin I, Sañudo. Arterial patterns of the human upper limb: Update of anatomical variations and embryological development. Eur J Anat. 2003; 7: 218.

9. T.S Ranganathan. A Textbook of Human Anatomy. Upper limb First edition 1982; 74

10. D'Costa S, Shenoy BM, Narayana K. The incidence of a superficial arterial pattern in the human upper extremities.Folia Morphol.2004; 63: 459-63.

11. Fuss FK, Matula CW, Tschabitscher M. Die Arteria brachialis superficialis. Anat ANZ. 1985; 160: 285-94.

12. Sajja LR, Mannam G, Pantula NR, Sompalli S. Role of Radial artery graft in coronary artery bypass grafting. Ann Thorac Surg. 2005; 79: 218. 


\section{CASE REPORT}

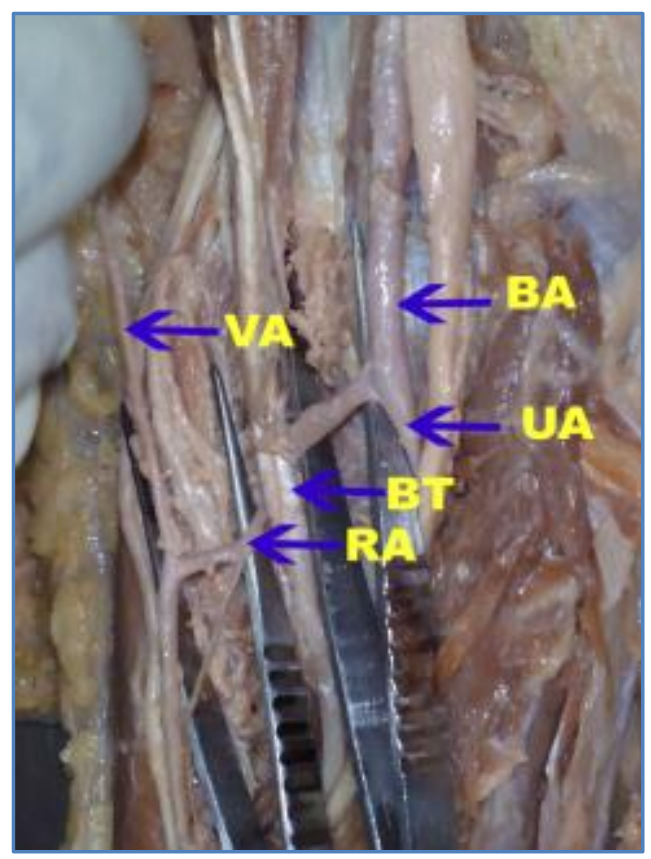

\section{Figure 1}

BA - Brachial Artery, UA - Ulnar Artery, RA - Radial Artery, VA - Vasa Aberrant BT - Biceps Tendon.

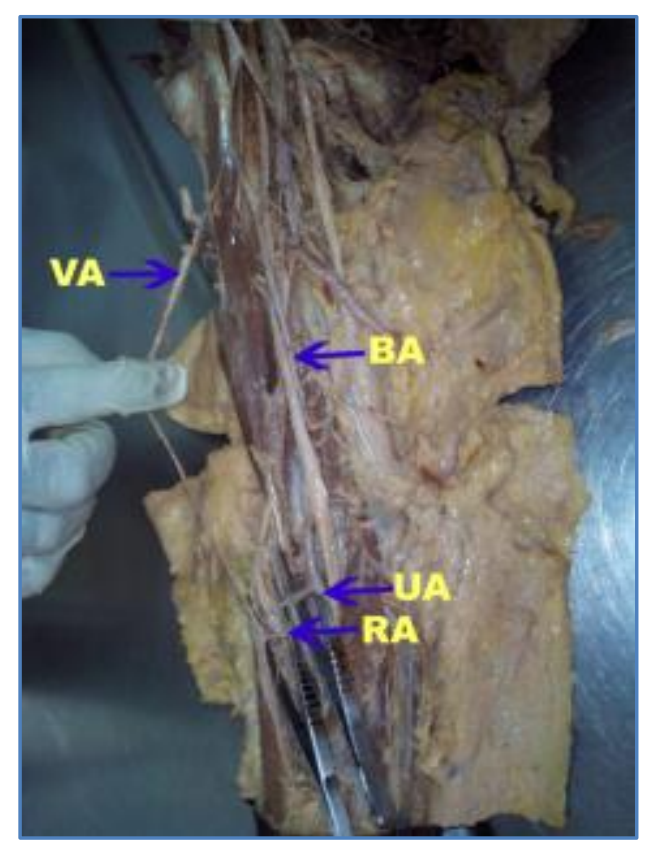

\section{Figure 2}

BA - Brachial Artery, UA - Ulnar Artery, RA - Radial Artery, VA - Vasa Aberrant BT - Biceps Tendon 


\section{CASE REPORT}

\section{AUTHORS:}

1. K. Manivannan

2. N. ShakuntalaRao

3. Gangadhara

4. H. R. Krishna Rao

\section{PARTICULARS OF CONTRIBUTORS:}

1. Assistant Professor, Department of Anatomy, P. E. S. Institute of Medical Sciences \& Research, Kuppam, Andhra Pradesh.

2. Professor, Department of Anatomy, P. E. S. Institute of Medical Sciences \& Research, Kuppam, Andhra Pradesh.

3. Associate Professor, Department of Anatomy, P. E. S. Institute of Medical Sciences \& Research, Kuppam, Andhra Pradesh.
4. Professor \& HOD, Department of Anatomy, P. E. S. Institute of Medical Sciences \& Research, Kuppam, Andhra Pradesh.

\section{NAME ADDRESS EMAIL ID OF THE CORRESPONDING AUTHOR:}

K. Manivannan, Assistant Professor, Department of Anatomy, PESIMSR, Kuppam,

Chittoor Dist, A. P. - 517425.

Email:maniroopaa@gmail.com

Date of Submission: 07/06/2014.

Date of Peer Review: 09/06/2014.

Date of Acceptance: 17/06/2014.

Date of Publishing: 23/06/2014. 